\title{
Publisher Correction: Economics of converting renewable power to hydrogen
}

Gunther Glenk iD and Stefan Reichelstein

Correction to: Nature Energy https://doi.org/10.1038/s41560-019-0326-1, published online 25 February 2019.

In the version of this Article originally published, the units for 'Electricity price, $p_{\mathrm{e}}$ ' and 'Subsidy: PP or PTC' in Table 1 and 'LCOE', 'Levelized PP', 'Levelized PTC', 'Wind energy profit margin', 'Conversion premium' and 'LFCH' in Table 2 were incorrectly given as ' $€ \mathrm{kWh}^{-1}$ ' for Germany and ' $\mathrm{US} \$ \mathrm{kWh}^{-1}$ ' for Texas; these should have read ' $€ \mathrm{c} \mathrm{kWh}^{-1}$ ' and ' $\mathrm{US} \$ \mathrm{c} \mathrm{kWh}^{-1}$ ', respectively. In Fig. 1 , the $\mathrm{y}$ axes labels were incorrectly given as ' $€ \mathrm{kWh}^{-1}$ ' for panel a (Germany) and ' $\mathrm{US} \$ \mathrm{kWh}^{-1}$ ' for panel b (Texas); these should have read ' $€ \mathrm{c} \mathrm{kWh}^{-1}$ ' and ' $\mathrm{US} \$ \mathrm{c} \mathrm{kWh}^{-1}$ ', respectively. These errors have now been corrected. 